\title{
Isolation and characterization of a strain of Rhodobacter sulfidophilus: a bacterium which grows autotrophically with dimethylsulphide as electron donor
}

\author{
Steven P. Hanlon, ${ }^{1}$ Robert A. Holt, ${ }^{3}$ Geoffrey R. Moore ${ }^{2}$ and \\ Alastair G. McEwan'† \\ Author for correspondence: Alastair G. McEwan. Tel: +617365 4878. Fax: +6173654620. \\ e-mail mcewan@ biosci.uq.oz.au
}

1,2 Centre for Metalloprotein Spectroscopy and Biology, School of Biological Sciences ${ }^{1}$ and School of Chemical Sciences ${ }^{2}$, University of East Anglia, Norwich NR4 7TJ, UK

3 Zeneca BioProducts, PO Box 2, Belasis Avenue, Billingham, Cleveland TS23 1YN, UK

\begin{abstract}
A marine photosynthetic bacterium (strain SH1) was isolated after enrichment under phototrophic conditions in media containing dimethylsulphide (DMS) and bicarbonate $\left(\mathrm{HCO}_{3}^{-}\right)$as potential carbon sources. Analysis of culture medium using nuclear magnetic resonance spectrometry showed that during phototrophic and chemotrophic growth of strain $\mathrm{SH} 1$ on $\mathrm{DMS} / \mathrm{HCO}_{3}^{-}$ dimethylsulphoxide (DMSO) was produced from DMS. These results indicate that strain SH1 grew autotrophically with DMS serving as an electron donor in photosynthesis and respiration, but not as a carbon source. Biochemical characterization and 165 rRNA analysis indicated that the isolate was a strain of Rhodobacter sulfidophilus. An assay for the enzyme catalysing the oxidation of DMS (DMS : acceptor oxidoreductase) was developed by measuring electron transfer from DMS to 2,6-dichlorophenolindophenol (DCPIP). This reaction was dependent on phenazine ethosulphate to mediate electron transfer from DMS : acceptor oxidoreductase to DCPIP. DMS : acceptor oxidoreductase was found to have a periplasmic location in strain SH1 as was a reduced methylviologen:DMSO oxidoreductase activity. Zymogram staining patterns of periplasmic fractions indicated that DMS : acceptor oxidoreductase and DMSO reductase were distinct enzymes. This was confirmed by resolution of the two activities by gel filtration.
\end{abstract}

Keywords: Dimethylsulphide oxidation, Rbodobacter sulfidopbilus

\section{INTRODUCTION}

Dimethylsulphide (DMS) is the most abundant organosulphur compound present in marine environments (Andreae \& Raemdonck, 1983) and recent studies indicate that export of DMS from the ocean accounts for up to half the total annual input of sulphur into the atmosphere (Bates et al., 1987). In marine environments the predominant source of DMS is dimethylsulphoniopropionate (DMSP), a compound which may serve as an osmolyte in marine algae (Reed, 1983; White, 1982). Microbial cleavage of DMSP to DMS and acrylate has been

†Present address: Department of Microbiology, University of Queensland, Brisbane, Qld 4072, Australia.

Abbreviations: DMS, dimethylsulphide; DMSO, dimethylsulphoxide; NMR, nuclear magnetic resonance; DCPIP, 2,6-dichlorophenolindophenol; DMSP, dimethylsulphoniopropionate; PES, phenazine ethosulphate. demonstrated in anoxic coastal marine sediments (Kiene \& Taylor, 1988) and bacteria which catalyse this reaction have been isolated (Dacey \& Blough, 1987). Since the amount of DMS entering the atmosphere is estimated to be less than $10 \%$ of the total amount produced (Kiene, 1993) there must be a number of biological routes of DMS consumption.

One potential route of DMS utilization is its oxidation to dimethylsulphoxide (DMSO), but there is very little information about bacterial species which could catalyse this reaction. Recently, purple sulphur bacteria have been isolated which are capable of photoautotrophic growth with DMS as electron donor (Zeyer et al., 1987). However, the only DMS-oxidizing phototroph which has been characterized is a strain of Thiocapsa roseopersicina, isolated from a microbial mat (Visscher \& van Gemerden, 1991). In view of the availability of DMS it seems likely that a 
large number of bacterial species with the ability to oxidize this molecule are, as yet, unidentified. In this paper we describe the isolation and characterization of a marine purple non-sulphur phototroph capable of utilizing DMS as an electron donor in autotrophic growth. We also report the development of an assay, using artificial electron acceptors, for the enzyme responsible for DMS oxidation (DMS: acceptor oxidoreductase). This assay was used to define the subcellular location of DMS : acceptor oxidoreductase.

\section{METHODS}

Growth media. A basal medium for growth of marine phototrophs was adapted from RCV medium described by Weaver et al. (1975) and is henceforth referred to as RCV-M. In $\mathrm{RCV}-\mathrm{M}$ organic carbon was omitted from the basal medium and it was supplemented with $\mathrm{NaCl}\left(25 \mathrm{~g} \mathrm{l}^{-1}\right)$ and $0.01 \%$ yeast extract which was added from filter sterilized stock solutions. For autotrophic growth of marine phototrophs, DMS (10 mM) and filter sterilized $\mathrm{NaHCO}_{3}$ were added to RCV-M medium. For photoheterotrophic growth of marine phototrophs the RCV-M medium was supplemented with sodium malate $(0.4 \%$, $\mathrm{w} / \mathrm{v}$ ) and filter sterilized DMSO to $50 \mathrm{mM}$.

Isolation of a DMS-oxidizing marine phototroph. Surface mud was collected from a tidal creek at Brancaster Staithe, Norfolk, UK in February 1992. Small samples of mud were used to inoculate the enrichment medium (RCV-M+DMS $/ \mathrm{HCO}_{3}^{-}$). Cultures were incubated under anaerobic conditions at $30^{\circ} \mathrm{C}$ in completely filled McCartney bottles between two banks of $100 \mathrm{~W}$ tungsten bulbs. For aerobic growth in the dark, flasks were shaken at 220 r.p.m. at $30^{\circ} \mathrm{C}$. For photoheterotropaic surface growth RCV-M was supplemented with $1.5 \%(\mathrm{w} / \mathrm{v})$ agar and the plates incubated at $30^{\circ} \mathrm{C}$ in anaerobic gas pack jars. For aerobic growth the plates were incubated at $30^{\circ} \mathrm{C}$ in the dark.

Absorption spectra. Whole cell absorption spectra were collected using a Phillips PU 8730 spectrophotometer. Cells were pelleted in an Eppendorf centrifuge and resuspended in $4 \mathrm{M}$ sucrose before collection of spectra.

Fractionation of cells and enzyme assays. Cells were harvested as described by McEwan et al. (1984) except that $25 \mathrm{~g} \mathrm{I}^{-1}$ was included in the washing buffer. DMSO reductase was measured by following the oxidation of dithionite-reduced methylviologen as described by McEwan et al. (1985). The DMS : acceptor oxidoreductase activity was measured under anaerobic conditions using phenazine ethosulphate (PES) and 2,6-dichlorophenolindophenol (DCPIP) as electron acceptors. The assay mixture was composed of $1 \mathrm{ml}$ of degassed $50 \mathrm{mM}$ Tris/ $\mathrm{HCl}, \mathrm{pH} 8 \cdot 0$, containing $1 \mu \mathrm{mol}$ PES and $90 \mathrm{nmol}$ DCPIP. After addition of sample to determine the DMS-independent rate of DCPIP reduction, the reaction was started by the addition of $20 \mathrm{mM}$ DMS from a $2 \mathrm{M}$ stock solution in ethanol. DCPIP reduction was followed by the decrease in absorbance at $600 \mathrm{nrn}$ in a single beam spectrophotometer. DMS:acceptor oxidoreductase activity was calculated from the extinction coefficient of DCPIP $\left(21.95 \mathrm{mM}^{-1} \mathrm{~cm}^{-1}\right)$.

16S rRNA sequence analysis. Partial 16S rRNA gene sequence was obtained by the method of Young et al. (1991). This work was performed by M. R. Knox and DNA sequences were analysed by Dr J. P. W. Young (then working at the John Innes Institute, Norwich, UK).

Quantitation of DMSO in growth media. Determination of: DMSO in growth media was performed using proton nuclear magnetic resonance ( $\left.{ }^{1} \mathrm{H}-\mathrm{NMR}\right)$ essentially as described by King et al. (1988). For the NMR analysis, $1 \mathrm{ml}$ samples were taken from $30 \mathrm{ml}$ cultures growing either photoautotrophically or chemoautotrophically on RCV-M plus DMS $/ \mathrm{HCO}_{3}^{-}$. The cells were pelleted in an Eppendorf centrifuge and $\mathrm{D}_{2} \mathrm{O}$ was added to $10 \%(\mathrm{v} / \mathrm{v})$. Acetone was used as an internal standard. The ${ }^{1} \mathrm{H}$ NMR spectra were recorded on either a $270 \mathrm{MHz}$ or $400 \mathrm{MHz}$ Jeol spectrometer.

Non-denaturing PAGE and zymogram staining for DMS:acceptor oxidoreductase and DMSO reductase activity. Protein samples were separated by electrophoresis on $10 \%$ acrylamide gels (30:0.8 acrylamide/bis-acrylamide) under non-denaturing conditions according to the method of Davis (1964). DMS : acceptor oxidoreductase activity was detected by soaking gels for $30 \mathrm{~min}$ in degassed $50 \mathrm{mM}$ Tris $/ \mathrm{HCl}, \mathrm{pH} 8.0$, containing $1 \mathrm{mM}$ PES and $300 \mu \mathrm{M}$ DCPIP then adding DMS to a final concentration of $20 \mathrm{mM}$. Negatively staining bands appeared within $2 \mathrm{~min}$. No bands appeared before the addition of DMS. Gels were stained for DMSO reductase activity by the method of Shimokawa \& Ishimoto (1979).

Sephacryl S-200 gel filtration of crude periplasm. Periplasm from $1 \mathrm{l}$ of cells grown photoheterotrophically on RCV-M plus malate/DMSO was concentrated to approx. $2 \mathrm{ml}$ by ultrafiltration (Amicon PM 10 filter) and applied to a Sephacryl S-200 (Pharmacia) column (bed volume $510 \mathrm{ml}$ ) equilibrated with $50 \mathrm{mM}$ Tris $/ \mathrm{HCl}$, pH 8.0 , containing $150 \mathrm{mM} \mathrm{NaCl}$. The column was eluted using the same buffer at a flow rate of $30 \mathrm{ml} \mathrm{h}^{-1} ; 7 \cdot 2 \mathrm{ml}$ fractions were collected and assayed for DMS : acceptor oxidoreductase and DMSO reductase.

\section{RESULTS}

\section{Isolation and characterization of a DMS-oxidizing purple phototrophic bacterium}

To enrich for DMS-oxidizing phototrophs samples of surface mud were inoculated into the RCV-M medium containing DMS as the only electron source and $\mathrm{HCO}_{3}^{-}$as an oxidized carbon source. After about $4 \mathrm{~d}$, the bottles of enrichment media inoculated with marine mud and incubated under illumination began to turn orange-brown in colour, indicating the growth of phototrophic bacteria. The inoculum was subcultured into the same medium several times to enrich for the DMS-oxidizing bacteria. Samples of $10 \mu \mathrm{l}$ were streaked onto agar plates of RCV$\mathrm{M}$ medium supplemented with $0.4 \%(\mathrm{w} / \mathrm{v})$ sodium malate. The plates were incubated either anaerobically in the light or aerobically in the dark. On the plates incubated under phototrophic conditions red-brown colonies were seen, together with a small number of colourless colonies. On the aerobic plates the bright red colonies of the putative phototrophs were quickly outgrown by large colonies of a colourless heterotroph. Single red colonies were repeatedly picked and streaked until no colonies of the colourless organism appeared on plates incubated under phototrophic or aerobic growth conditions. Stocks of these pure isolates were prepared and phototrophic growth on RCV-M plus DMS/ $\mathrm{HCO}_{3}^{-}$was confirmed. The properties of one of these isolates (henceforth referred to as strain SH 1) was further investigated. The following vitamin supplement was found to replace yeast extract in the medium used for growth of strain $\mathrm{SH}$ 1: $100 \mu \mathrm{g} \mathrm{l}^{-1}$ biotin, $1 \mathrm{mg}^{-1}$ nicotinic acid, $200 \mu \mathrm{g} \mathrm{l}^{-1}$ para- 


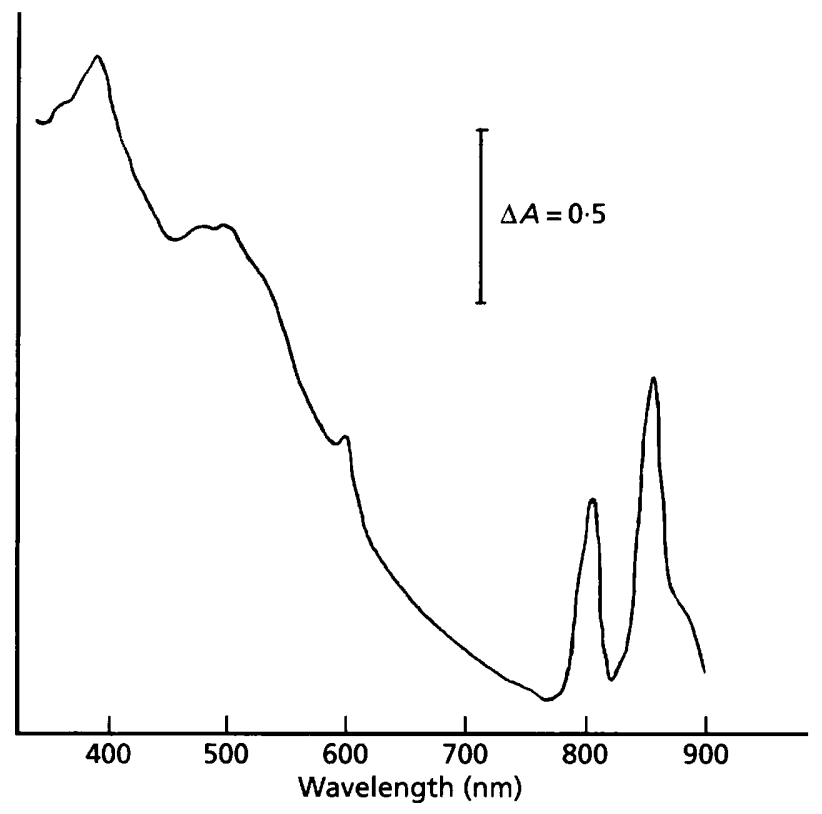

Fig. 1. Absorption spectrum of a phototrophically grown culture of strain SH 1.

aminobenzoic acid, and this mixture was used in all subsequent experiments.

Fig. 1 shows a whole cell absorption spectrum of strain SH 1 grown photoheterotrophically on RCV-M plus malate/DMSO. The absorption maxima at $376 \mathrm{~nm}$, $590 \mathrm{~nm}, 804 \mathrm{~nm}, 850 \mathrm{~nm}$ and the shoulder at $870 \mathrm{~nm}$ are indicative of bacteriochlorophyll a (Clayton, 1963). The absorption maxima between $400 \mathrm{~nm}$ and $500 \mathrm{~nm}$ are probably due to carotenoids of the spheroidine type. The photosynthetic pigment spectrum of strain $\mathrm{SH} 1$ is similar to the spectra described in purple non-sulphur phototrophs of the genus Rhodobacter (Clayton, 1963) and was quite distinct from that of the DMS-oxidizing purple sulphur phototroph $T$. roseopersicina (Vredenberg \& Amesz, 1966). The periplasm of strain SH 1 was also examined spectroscopically and was found to contain a number of $c$-type cytochromes. The most abundant of these cytochromes was reducible with ascorbate and had an absorption maximum at $556 \mathrm{~nm}$. Strain SH 1 was also able to utilize the $C_{1}$ compounds methylamine, trimethylamine and methanol during phototrophic growth (data not shown). Strain SH 1 was identified as Rhodobacter sulfidophilus by comparison of a partial 16S rRNA gene sequence with entries in the DDJB sequence data library (J.P. W. Young \& M. R. Knox, personal communication).

\section{Identification of DMSO as the product of DMS oxidation during photoautotrophic and chemoautotrophic growth of strain SH 1}

Strain SH 1 was not able to grow phototrophically on RCV-M supplemented with DMS unless $\mathrm{HCO}_{3}^{-}$was included. This implies that DMS was not being used as a
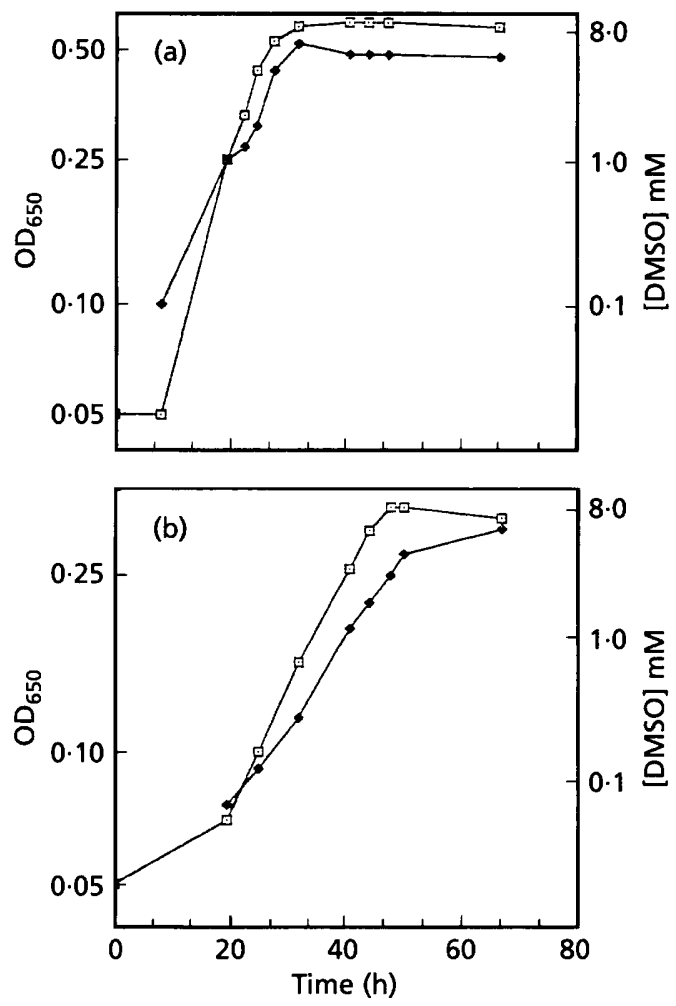

Fig. 2. Accumulation of DMSO during photoautotrophic (a) and chemoautotrophic (b) growth of strain SH 1. DMS was present at $10 \mathrm{mM}$ at the start of the experiment. DMSO accumulation; $\square$, bacterial growth.

carbon source and was being used only as an electron donor. If this were the case then it was expected that the product of DMS oxidation, DMSO, would accumulate during growth of strain SH 1. Strain SH 1 grew with doubling times of $7 \cdot 1 \mathrm{~h}$ and $12.5 \mathrm{~h}$ under photoautotrophic conditions and chemoautotrophic conditions respectively (Fig. 2a, b). The increase in optical density was paralleled by increased levels of DMSO in the growth medium as determined by NMR analysis (Fig. 2a, b). Moreover, the levels of DMSO did not increase when the cells reached stationary phase. Under both growth conditions DMSO accumulated to $60-70 \%$ of the initial DMS concentration by the time the cultures had reached stationary phase. The accumulation of DMSO in a control incubated in the light with no inoculum was $675 \mu \mathrm{M}$. This was presumably due to photochemical oxidation of DMS.

\section{Cellular location and levels of DMS: acceptor oxidoreductase}

DMS : acceptor oxidoreductase activity was released in a water-soluble form after treatment of cells with lysozyme/EDTA during fractionation (Table 1). Malate dehydrogenase was used as a cytoplasmic marker and the relatively large proportion of this enzyme in the periplasmic fraction is probably due to rupture of a proportion of spheroplasts, since it was noted that strain SH 1 was far more sensitive to EDTA-induced lysis than was $R$. 
Table 1. Cellular location of DMS: acceptor oxidoreductase in $R$. sulfidophilus strain $\mathrm{SH} 1$

Measurements were made on subcellular fractions prepared from $2 \mathrm{~g}$ (wet weight) of cells grown photoautotrophically on $\mathrm{DMS} / \mathrm{HCO}_{3}^{-}$.

\begin{tabular}{|lcc|}
\hline & $\begin{array}{c}\text { DMS:acceptor } \\
\text { oxidoreductase } \\
\text { activity (units) }\end{array}$ & $\begin{array}{c}\text { Malate } \\
\text { dehydrogenase } \\
\text { activity (units) }\end{array}$ \\
\hline Periplasm & $700 \cdot 0$ & $9 \cdot 2$ \\
$\begin{array}{l}\text { Membranes } \\
\text { cytoplasm }\end{array}$ & $34 \cdot 2$ & $26 \cdot 5$ \\
\hline
\end{tabular}

capsulatus. Table 2 shows the specific activities of DMS : acceptor oxidoreductase and DMSO reductase present in periplasmic fractions of strain $\mathrm{SH} 1$ grown under different phototrophic conditions. The two activities were high in fractions from cells grown photoautotrophically on RC.V$\mathrm{M}$ plus DMS $/ \mathrm{HCO}_{3}^{-}$compared to those from cells grown photoheterotrophically on RCV-M plus malate. When DMSO was included during photoheterotrophic growth, DMSO reductase and DMS:acceptor oxidoreductase activities were also elevated (Table 2).

\section{Resolution of DMS: acceptor oxidoreductase and DMSO reductase activities by non-denaturing PAGE and gel filtration}

Many species of purple non-sulphur phototrophic bacteria
Table 2. Specific activities of DMS: acceptor oxidoreductase and DMS reductase

Enzyme activities were assayed in periplasmic fractions of $R$. sulfidophilus strain SH 1 grown under different phototrophic conditions

\begin{tabular}{|c|c|c|}
\hline Growth medium & $\begin{array}{l}\text { DMS : acceptor } \\
\text { oxidoreductase } \\
\text { (units } \mathbf{m g}^{-1} \text { ) }\end{array}$ & $\begin{array}{c}\text { DMSO } \\
\text { reductase } \\
\text { (units } \mathrm{mg}^{-1} \text { ) }\end{array}$ \\
\hline $\begin{array}{l}\text { RCV-M plus } \\
\text { malate }\end{array}$ & $0 \cdot 0$ & 0.06 \\
\hline $\begin{array}{l}\text { RCV-M plus } \\
\text { malate/DMSO }\end{array}$ & $58 \cdot 3$ & $0 \cdot 38$ \\
\hline $\begin{array}{l}\mathrm{RCV}-\mathrm{M} \text { plus } \\
\mathrm{DMS} \mathrm{HCO}_{3}\end{array}$ & $25 \cdot 1$ & 0.54 \\
\hline
\end{tabular}

possess a periplasmic DMSO reductase which terminates an anaerobic respiratory chain (Ferguson et al., 1987). This enzyme catalyses the reduction of DMSO to DMS, the reversal of the reaction catalysed by DMS:acceptor oxidoreductase. Since strain SH 1 appeared to possess DMSO reductase and DMS:acceptor oxidoreductase activities in the periplasm (Table 2) this raised the possibility that the two reactions were catalysed by a single enzyme. To address this question, polypeptides in periplasmic fractions were separated by electrophoresis under non-denaturing conditions and zymogram patterns for DMSO reductase activity were examined. In periplasm

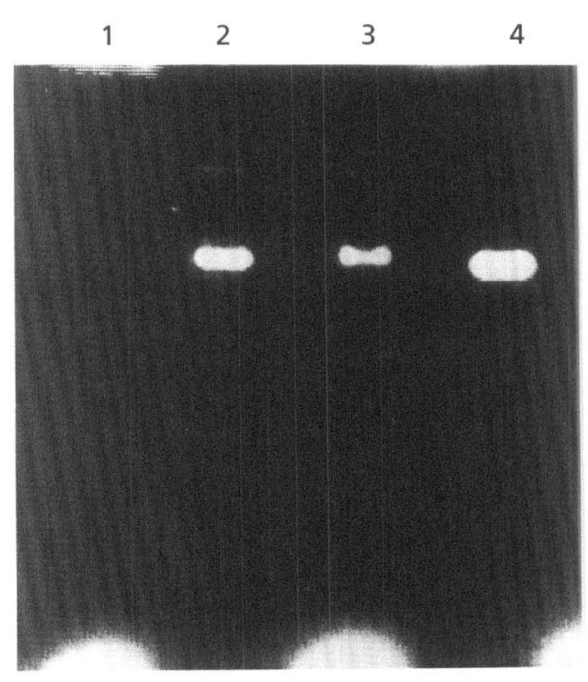

Fig. 3

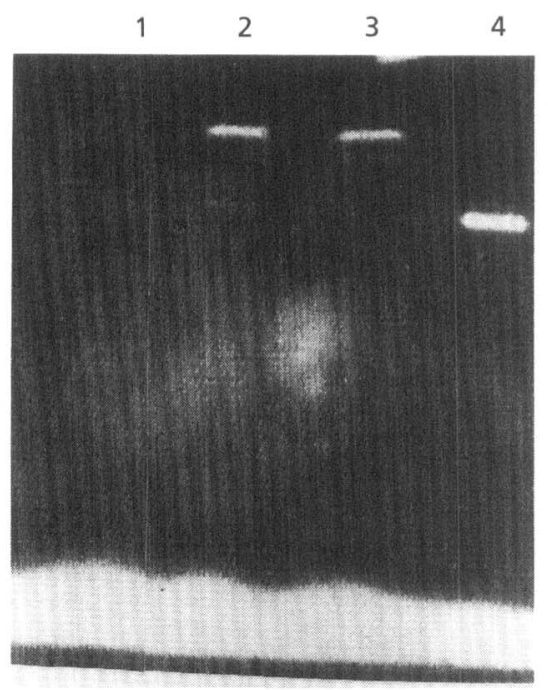

Fig. 4

Fig. 3. Zymogram staining of a $10 \%$ PAGE gel for DMSO reductase activity. Lanes 1, 2 and 3 each contain $15 \mu \mathrm{g}$ periplasmic fraction prepared from phototrophically grown strain SH 1. Lane 1, RCV-M plus malate; lane 2, RCV-M plus $\mathrm{DMS} \mathrm{HCO}_{3}^{-}$; lane 3, RCV-M plus malate/DMSO; lane 4, $5 \mu \mathrm{g}$ purified DMSO reductase ( $R$. capsulatus).

Fig. 4. Zymogram staining of a $10 \%$ PAGE gel for DMS: acceptor oxidoreductase activity. lanes 1,2 and 3 each contain $15 \mu \mathrm{g}$ periplasmic fraction prepared from phototrophically grown strain SH 1. Lane 1, RCV-M plus malate; lane $2, \mathrm{RCV}-\mathrm{M}$ plus $\mathrm{DMS} / \mathrm{HCO}_{3}^{-}$; lane 3, RCV-M plus malate/DMSO; lane $4,5 \mu \mathrm{g}$ purified DMSO reductase ( $R$. capsulatus). 


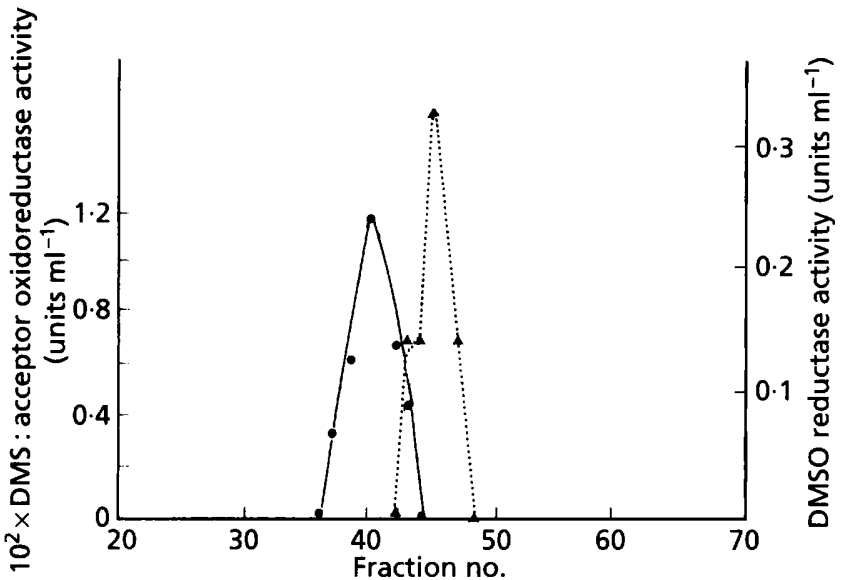

Fig. 5. Gel filtration of periplasm containing DMS:acceptor oxidoreductase (O) and DMSO reductase $(\boldsymbol{\Delta})$ activities.

from cells grown photoheterotrophically in the absence of DMS or DMSO, no activity staining band was observed (Fig. 3, lane 1). However, in cells grown photoautotrophically with DMS (Fig. 3, lane 2) or photoheterotrophically in the presence of DMSO (Fig. 3, lane 3), single intense activity staining bands were observed. The $R_{F}$ value for these bands was identical to that of DMSO reductase purified from $R$. capsulatus (McEwan et al., 1991) (Fig. 3, lane 4). In lanes 2 and 3 (Fig. 3) an additional band was identified which stained extremely weakly for DMSO reductase activity. This protein had lower electrophoretic mobility than DMSO reductase. Fig. 4 shows a non-denaturing PAGE gel of the periplasmic fractions described in Fig. 3 stained for DMS:acceptor oxidoreductase activity. The gel was stained blue-green with oxidized DCPIP and activity was indicated as a negatively staining band (reduced DCPIP). This zymogram revealed that intense DMS: acceptor oxidoreductase activity (Fig. 4 , lanes 2 and 3) was associated with a protein with electrophoretic mobility identical to the band which stained weakly for DMSO reductase activity (Fig. 3, lanes 2 and 3). No bands staining for DMS: acceptor oxidoreductase activity were identified with the same electrophoretic mobility as $R$. capsulatus DMSO reductase (Fig. 4 , lane 4), although this purified DMSO reductase did appear to be able to catalyse electron transfer from DMS to DCPIP.

The above data implied that DMSO reductase and DMS : acceptor oxidoreductase were distinct enzymes. A concentrated periplasmic fraction was applied to a Sephacryl S-200 column with the aim of resolving the two activities. The DMS:acceptor oxidoreductase activity eluted first at approx. $290 \mathrm{ml}$, while the peak of DMSO reductase activity eluted at $330 \mathrm{ml}$ (Fig. 5). The near-tobaseline separation of the two activity peaks provided further evidence that DMS: acceptor oxidoreductase and DMSO reductase were distinct enzymes. The results also indicated that DMS : acceptor oxidoreductase had a higher native molecular mass than DMSO reductase.

\section{DISCUSSION}

There are few examples of bacteria able to utilize DMS as an electron donor, although the widespread occurence of DMS, especially in marine environments, suggests that this capability might be a property of a diverse range of bacterial species. The accumulation of DMSO during growth of phototrophic bacteria described in this work and elsewhere (Visscher \& van Gemerden, 1991) is consistent with DMS being used only as an electron donor and not as a carbon source. Previous characterization of DMS-oxidizing phototrophs has been restricted to T. roseopersicina (Visscher \& van Gemerden, 1991) and Thiocystis sp. (Zeyer et al., 1987). Although Zeyer et al. (1987) indicated that one of their DMSoxidizing bacterial isolates might be a Rhodospirillum, the characterization of strain $\mathrm{SH} 1$ is the first strong evidence that certain purple non-sulphur bacteria are able to use DMS as electron donor during phototrophic growth. Strain SH 1 has been identified as Rhodobacter sulfidophilus by analysis of its $16 \mathrm{~S}$ rRNA gene sequence and it was found to cluster with the three strains of R. sulfidophilus in the database. The next closest species is Rhodobacter adriaticus with other $R$ hodobacter species being significantly more distant. The ability to use DMS as an electron donor was also a property of $R$. sulfidophilus strain DSM 1374 but this strain differed from strain SH 1 in being unable to grow with methanol or methylamine as carbon sources (S. P. Hanlon, unpublished observations). It seems likely that a number of purple non-sulphur bacteria can oxidize DMS. However, this capability is probably restricted to marine species since efforts to grow Rhodobacter sphaeroides and R. capsulatus under these conditions were unsuccessful (S. P. Hanlon \& A. G. McEwan, unpublished observations).

Our results also show that DMS was used by strain SH 1 solely as an electron donor in chemoautotrophic growth. This contrasts with the use of DMS by Thiobacillus species (Kanagawa \& Kelly, 1986; Smith \& Kelly, 1988a, b) and two isolates of Hyphomicrobium (De Bont et al., 1981; Suylen et al., 1987). Thiobacillus and Hyphomicrobium are able to generate sulphide from DMS and sulphide is then oxidized during respiratory electron transfer to sulphate (Kanagawa \& Kelly, 1986; Suylen et al., 1987). Carbon assimilation is via $\mathrm{CO}_{2}$ fixation in Thiobacillus (Kanagawa \& Kelly, 1986) while in Hyphomicrobium formaldehyde generated during DMS catabolism is assimilated via the serine pathway (De Bont $e t$ al., 1981). In these cases DMS serves as both an electron source and carbon source.

Zhang et al. (1991) isolated a strain of Pseudomonas acidovorans which can oxidize DMS to DMSO under aerobic conditions. However, this bacterium cannot grow under chemoautotrophic conditions, presumably because it is unable to fix $\mathrm{CO}_{2}$ via the Calvin cycle. It is possible that the ability to use DMS as an electron donor may be a property of a number of chemoheterotrophs, but this capability has been overlooked because of the lack of suitable enrichment media.

Finally, the development of an assay for DMS:acceptor oxidoreductase activity has opened the way for an analysis 
of the properties of this enzyme. The zymogram staining patterns and the gel filtration elution profile (Figs 3, 4 and 5) strongly support the view that DMS:acceptor oxidoreductase and DMSO reductase are distinct enzymes.

\section{ACKNOWLEDGEMENTS}

S. P. H. thanks SERC (UK) and Zeneca BioProducts for a CASE studentship. A. G. M. and G. R. M. thank SERC for support for the Centre for Metalloprotein Spectroscopy and Biology via the Molecular Recognition Initiative. We thank Professor J. P. W. Young and Mrs M. R. Knox for carrying out the $16 \mathrm{~S}$ rRNA analysis.

\section{REFERENCES}

Andreae, M. O. \& Raemdonck, H. (1983). Dimethylsulfide in the surface ocean and the marine atmosphere. A global view. Science 221, 744-747.

Bates, T. S., Charlson, R. J. \& Gammon, R. H. (1987). Evidence for the climatic role of marine biogenic sulphur. Nature 329, 319-321.

Clayton, R. K. (1963). Absorption spectra of photosynthetic bacteria and their chlorophylls. In Bacterial Pbotosynthesis, pp. 495-500. Edited by H. Gest, A. San Pietro \& L. P. Vernon. Yellow Springs, Ohio: Antioch Press.

Dacey, J. W. H. \& Blough, N. V. (1987). Hydroxide decomposition of dimethylsulfoniopropionate to form dimethylsulfide. Geopbys Res Lett 14, 1246-1249.

Davis, B. J. (1964). Disc electrophoresis. II. Method and application to human serum proteins. Ann NY Acad Sci 121, 404-427.

De Bont, J. A. M., van Dijken, J.P. \& Harder, W. (1981). Dimethylsulphoxide and dimethylsulphide as a carbon and energy source for growth of Hyphomicrobium S. J Gen Microbiol 127, 315-323.

Ferguson, S. J., Jackson, J. B. \& McEwan, A. G. (1987). Anaerobic respiration in the Rhodospirillaceae. Characterization of pathways and evaluation of roles in redox balancing during photosynthesis. FEMS Microbiol Lett 46, 117-143.

Kanagawa, T. \& Kelly, D.P. (1986). Breakdown of dimethylsulphide by mixed cultures and by Thiobacillus thioparus. FE.MS Microbiol Lett 34, 13-19.

Kiene, R. P. (1993). Microbial sources and sinks for methylated sulfur compounds in the marine environment. In Microbial Groizth on $C_{1}$ Compounds, pp. 15-30. Edited by J. C. Murrell \& D. P. Kelly. Andover, UK: Intercept.

Kiene, R. P. \& Taylor, B. F. (1988). Demethylation of dimethylsulfoniopropionate and production of thiols in anoxic marine environments. Appl Environ Microbiol 54, 2208-2212.

King, G. F., Richardson, D. J., Jackson, J. B. \& Ferguson, S. J. (1988). Dimethylsulphoxide and trimethylamine- $N$-oxide as bacterial electron acceptors: use of nuclear magnetic resonance to assay and characterize the reductase system in Rhodobacter capsulatus. Arch Microbiol 149, 47-51.

McEwan, A. G., Jackson, J. B. \& Ferguson, S. J. (1984). Rationalization of the properties of nitrate reductase in Rhodopseudomonas capsulata. Arch Microbiol 137, 344-349.

McEwan, A. G., Wetzstein, H. G., Ferguson, S. J. \& Jackson, J. B. (1985). Periplasmic location of the terminal reductase in trimethylamine- $N$-oxide and dimethylsulphoxide respiration in the photosynthetic bacterium Rhodopseudomonas capsulata. Biochim Biophys Acta 806, 410-417.

McEwan, A. G., Ferguson, S. J. \& Jackson, J. B. (1991). Purification and properties of dimethylsulphoxide reductase from Rhodobacter capsulatus. Biochem J 274, 305-307.

Reed, R. H. (1983). Measurement and osmotic significance of $\beta$ dimethylsulfoniopropionate in marine macroalgae. Marine Biol Lett 34, 173-181.

Shimokawa, O. \& Ishimoto, M. (1979). Purification and some properties of inducible tertiary amine $N$-oxide reductase from Escherichia coli. J Biochem 86, 1709-1717.

Smith, N. A. \& Kelly, D. P. (1988a). Isolation and physiological characterization of autotrophic bacteria oxidizing dimethylsulphide as a sole source of energy. J Gen Microbiol 134, 1407-1417.

Smith, N. A. \& Kelly, D. P. (1988b). Mechanism of oxidation of dimethylsulphide by Thiobacillus thioparus strain E6. J Gen Microbiol 134, 3041-3048.

Suylen, G. M. H., Large, P. J., van Dijken, J. P. \& Kuenen, J. G. (1987). Methyl mercaptan oxidase, a key enzyme in the metabolism of methylated sulphur compounds by Hyphomicrobium EG. J Gen Microbiol 133, 2989-2997.

Visscher, P. P. \& van Gemerden, H. (1991). Photo-autotrophic growth of Thiocapsa roseopersicina on dimethylsulphide. FEMS Microbiol Lett 81, 247-250.

Vredenberg, W. J. \& Amesz, J. (1966). Absorption bands of bacteriochlorophyll types in purple bacteria. Biochim Biopbys Acta 126, 244-253.

Weaver, P. T., Wall, J. D. \& Gest, H. (1975). Characterization of Rhodopseudomonas capsulata. Arch Microbiol 105, 207-216.

White, R. H. (1982). Analysis of dimethylsulfonium compounds in marine algae. J Mar Res 40, 529-536.

Young, J. P. W., Dowener, H. L. \& Eardly, B. D. (1991). Phylogeny of the phototrophic Rbizobium strain BTAL/1 by polymerase chain reaction-based sequencing of a $16 \mathrm{~S}$ rRNA gene segment. J Bacteriol 173, 2271-2277.

Zeyer, J., Eicher, P., Wakeham, S. G. \& Schwarzenbach, R.P. (1987). Oxidation of dimethylsulfide to dimethylsulfoxide by purple phototrophic bacteria. Appl Environ Microbiol 53, 2026-2032.

Zhang, L., Kuniyoshi, I., Hirai, M. \& Shoda, M. (1991). Oxidation of dimethylsulphide by Pseudomonas acidovorans DMR-11 isolated from a peat filter. Biotechnol Lett 13, 223-228.

Received 2 November 1993; revised 18 February 1994; accepted 1 March 1994 